Canadian Journal of Higher Education

Revue canadienne d'enseignement supérieur

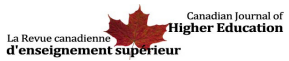

\title{
Gender and the Faculty Care Gap: "The Obvious Go-To Person" for Canadian University Students' Personal Problems
}

\author{
Jennifer Dengate, Tracey Peter and Annemieke Farenhorst
}

Volume 49, Number 3, 2019

URI: https://id.erudit.org/iderudit/1066638ar

DOI: https://doi.org/10.7202/1066638ar

\section{See table of contents}

Publisher(s)

Canadian Society for the Study of Higher Education

ISSN

2293-6602 (digital)

Explore this journal

Cite this article

Dengate, J., Peter, T. \& Farenhorst, A. (2019). Gender and the Faculty Care Gap: "The Obvious Go-To Person" for Canadian University Students' Personal Problems. Canadian Journal of Higher Education / Revue canadienne d'enseignement supérieur, 49(3), 104-114. https://doi.org/10.7202/1066638ar
Article abstract

A mixed methods analysis of Canadian natural sciences and engineering faculty's workplace experiences revealed a gendered care gap with women reporting greater responsibility for students' personal and mental health problems, including suicidal thoughts and behaviour, and sexual assault. Statistical results demonstrated that women were approached by a significantly greater number of students to discuss serious non-academic issues and experienced more stress as a result. A comparative qualitative analysis found faculty's responses to students' problems were informed by gendered cultural care expectations thatrequire women to be more supportive than men. However, female and male faculty's care burden may also be exacerbated by institutional factors, including senior administrative positions, undergraduate class loads, and teaching courses with mental health-related content. As such, the care gap is relevant to understanding the extent to which gender inequality is embedded within the structure of universities.
This document is protected by copyright law. Use of the services of Érudit (including reproduction) is subject to its terms and conditions, which can be viewed online.

https://apropos.erudit.org/en/users/policy-on-use/ 


\title{
GENDER AND THE FACULTY CARE GAP: "THE OBVIOUS GO-TO PERSON" FOR CANADIAN UNIVERSITY STUDENTS' PERSONAL PROBLEMS
}

\author{
JENNIFER DENGATE \\ UNIVERSITY OF MANITOBA
}

\author{
TRACEY PETER \\ UNIVERSITY OF MANITOBA
}

\author{
ANNEMEKE FARENHORST \\ UNIVERSITY OF MANITOBA
}

\begin{abstract}
A mixed methods analysis of Canadian natural sciences and engineering faculty's workplace experiences revealed a gendered care gap with women reporting greater responsibility for students' personal and mental health problems, including suicidal thoughts and behaviour, and sexual assault. Statistical results demonstrated that women were approached by a significantly greater number of students to discuss serious non-academic issues and experienced more stress as a result. A comparative qualitative analysis found faculty's responses to students' problems were informed by gendered cultural care expectations that require women to be more supportive than men. However, female and male faculty's care burden may also be exacerbated by institutional factors, including senior administrative positions, undergraduate class loads, and teaching courses with mental health-related content. As such, the care gap is relevant to understanding the extent to which gender inequality is embedded within the structure of universities.
\end{abstract}

Keywords: science, engineering, Canada, faculty, gender, caregiving

\section{Résumé}

Une analyse à méthode mixte effectuée auprès du corps professoral canadien en sciences naturelles et en ingénierie signale un écart entre les genres/les sexes quant au soutien fourni auprès de la population étudiante. En effet, les femmes rapportent une responsabilité accrue à l'égard de la santé personnelle et mentale de la population étudiante, y compris la gestion des pensées suicidaires et des cas d'agression sexuelle. Selon les statistiques, les femmes seraient approchées par un plus grand nombre d'étudiants et d'étudiantes pour discuter de sujets non universitaires, ce qui entraînerait pour elles un taux de stress accru. Une analyse comparative de nature qualitative indique que le corps professoral a tendance à gérer les cas d'étudiants et d'étudiantes selon des normes culturelles genrées, en vertu desquelles les femmes seraient plus disposées à offrir du soutien que les hommes. Toutefois, certains facteurs institutionnels contribuent à accroître cette charge émotionnelle, notamment les postes administratifs, la charge d'enseignement et l'enseignement de cours dont le contenu touche les questions de santé mentale, et peuvent exacerber l'écart entre les genres/les sexes. Afin de mieux comprendre comment et pourquoi l'inégalité entre les sexes est structurante dans le contexte universitaire, il ne faut pas négliger le rôle de l'écart quant au soutien offert à la population étudiante.

Mots-clés : sciences, ingénierie, Canada, la faculté, le genre, soins

\section{Introduction}

Universities are argued to be gendered organizations, characterized by a division of labour and "asymmetric" reward hierarchy that disproportionately assigns women the least valued work (e.g., service), detracting from highly valued research activity (Bird, Litt, \& Wang, 2004; Misra, Lundquist, Holmes, \& Agiomavritis, 2011; Park, 1996). This research investigates an additional task for which women appear disproportionately responsible, one even less visible than service: caring for students (Acker \& Feuerverger, 1996).

We focus on the division of care work within male-dominated natural sciences and engineering (NSE) units. Women remain underrepresented in American NSE and continue to experience harassment and discrimination, exclusion within their units, and report less access to equipment, for example (Fox, 2010; Settles, 
Cortina, Malley, \& Stewart, 2006). Similarly, women are underrepresented in Canadian NSE, are less likely than men to be full professors, and may experience promotion delays (Canadian Association of University Teachers, 2018; Ornstein, Stewart, \& Drakich, 2007). Thus, greater responsibility for student care would constitute another gender-based barrier to equality for women in NSE.

Our mixed methods analysis describes instances in which Canadian NSE faculty interact with students facing personal and mental health-related issues. Bivariate statistical analyses answer the following questions: Do women have more non-academic interactions with students than men do and do they experience more stress as a result? An inductive qualitative analysis explores the ways in which faculty's perceived behaviour reproduces gendered care expectations (e.g., men are more emotionally distant than women). We ask: How do male and female faculty perceive their role in students' personal lives and potential consequences for non-academic student engagement?

\section{Literature Review}

We begin by describing the gendered distribution of student care work, including possible cultural and institutional explanations. We then explore one potential pathway between student care work and faculty well-being via emotional labour (Hochschild, 2012). By considering evidence of a gendered division of academic labour within the framework of "doing gender" (West \& Zimmerman, 1987), we emphasize the role of gendered faculty-student interactions in maintaining and reproducing structural gender inequality within academia (e.g., Acker, 1990).

A substantial literature describes women's greater responsibility for "tak[ing] care of the academic family" (Guarino \& Borden, 2016, p. 19). "Care" often refers to service (e.g., committees) (Bird et al., 2004; O'Meara, 2016), since service, teaching, and research are the activities traditionally assessed in tenure decisions (Acker, Webber, \& Smyth, 2012). However, female faculty from Canada, the United Kingdom, and the United States also felt pressure to tend to students' emotional needs (e.g., Acker \& Feuerverger, 1996; Bagilhole \& Goode, 1998; Barnes-Powell \& Letherby, 1998). Yet, faculty's care efforts may not always align with research, teaching, or service. Care is connected to teaching insofar as students seek concessions to manage personal challenges (e.g., requesting a deadline extension). It may be cred- ited as service if faculty are acting as student advisors (e.g., Barnes-Powell \& Letherby, 1998). Even so, the institutional worth of advising pales in comparison to publications and successful grants (Nadler, M. K. \& Nadler, L. B., 1993). Thus, in and outside of these scenarios, caring for students appears largely taken for granted (Acker \& Feuerverger, 1996).

Acker and Feuerverger (1996) described students coming to Canadian female education faculty's offices in tears, displaying delusional behaviour, and discussing self-harm. Similarly, American female faculty from various departments felt they "should" listen to students' problems outside of the classroom, linking their students' personal issues to subsequent academic difficulties (Statham, Richardson, \& Cook, 1991, p. 95). Indeed, many students expected female advisors would be "there for them" and provide support (Barnes-Powell $\&$ Letherby, 1998, p. 74; Bellas, 1999). Male faculty were more likely to consider personal problems as an annoyance, with some discouraging further interaction by explaining that they were "not a counselor" (Statham et al., 1991, p. 97).

\section{Cultural and Institutional Explanations for the Gendered Care Gap}

Because they have traditionally done more unpaid labour (e.g., childrearing), the expectation that women are more nurturing can "silently" become part of their paid job descriptions (Hochschild, 2012, p. 170). Indeed, perceiving women to be warmer and more empathetic, U.S. students preferred female advisors (Mottarella, Fritzsche, \& Cerabino, 2004; Nadler, M. K. \& Nadler, L. B., 1993), which may lead to heavier student loads. Junior students with female advisors were more likely to discuss personal problems and the likelihood of such interactions grew over time. Ultimately, this increases the amount of time that female faculty spend on non-academic issues, detracting from their scholarly work (Nadler, M. K. \& Nadler, L. B., 1993).

Similarly, women are more likely to occupy the junior faculty ranks in Canada and these positions can include teaching large undergraduate classes (CAUT, 2018; Park, 1996). Women may also be more likely to teach courses that can encourage disclosures of domestic violence, eating disorders, and substance abuse (e.g., women's studies) (Barnes-Powell \& Letherby, 1998). As 
such, institutional roles may position certain faculty (of both genders) to encounter more students seeking support. So, why don't women, in particular, "just say no" to devalued labour (Pyke, 2011)?

Many women genuinely care for students and value this work (Acker \& Feuerverger, 1996). However, women may also be held accountable when they deviate from notions of "appropriate" feminine behaviour (West \& Zimmerman, 1987). To avoid falling short as female professors (Acker \& Feuerverger, 1996), they "do" their gender by aligning their conduct with cultural expectations (e.g., showing concern) (West \& Zimmerman, 1987). Similarly, by declining to become involved in students' personal lives, male faculty may also be doing gender; aligning their conduct with expectations of emotionally-reserved masculinity. Indeed, students evaluated female instructors more harshly on measures of support than men. Despite giving more time and attention to students, women were still more likely to be rated insufficiently available (Bennett, 1982).

\section{Emotional labour and well-being}

Faculty may also be performing "emotional labour" when approached by students; actively reconciling their actual feelings with how they should ideally feel (or appear to feel), given their work context (and gender) (Hochschild, 2012). Not actually feeling as an (male or female) employee "should" can create strain and aligning actual and ideal feelings, by either pretending or genuinely changing one's emotional state, requires effort (Hochschild, 2012).

Repeated interactions with students, pressure of course evaluations, and ambiguous rules governing professors' emotional displays may increase faculty's emotional labour (e.g., to create a favourable impression) (Mahoney, Buboltz, Buckner, \& Doverspike, 2011, pp. 407-408). Accordingly, if female faculty are expected to be more caring, have more non-academic encounters, and do more emotional labour, we might also expect gender differences in faculty stress. However, existing evidence linking emotional labour and faculty well-being is limited. Ogbonna and Harris (2004) found an increase in emotional labour and stress amongst U.K. university lecturers related to work intensification (e.g., pretending not to care about publishing). In contrast, American professors expressing genuine negative emotions (as one might expect to accompany distressing student disclosures) reported more emotional exhaustion than those who suppressed or faked their feelings (Mahoney et al., 2011).
The literature suggests that expectations of women's caring "natures" and institutional roles (e.g., advisor) may interact to increase their number of non-academic student encounters (e.g., Barnes-Powell \& Letherby, 1998). Moreover, women may be penalized for not acting sufficiently supportive (Bennett, 1982; West \& Zimmerman, 1987). Therefore, we expect female NSE faculty to report having more non-academic student disclosures and to do more care work than their male colleagues; and to describe more professional penalties and stress as a result.

\section{Methodology}

We administered a cross-sectional workplace experiences survey to NSE faculty from five Canadian universities, including medical/doctoral and comprehensive institutions. The sampling frame was constructed through university websites: 1,883 NSE faculty were emailed a link to complete the survey online and 421 completed the survey, representing a response rate of $22 \%$. The survey covered a number of topics expected to influence workplace climate, including harassment, discrimination, and workload density.

Nearly two-thirds $(65.4 \%)$ of the sample was male and $34.6 \%$ was female. Half were full professors $(49.7 \%)$ and the mean age was 50 years old. Associate and assistant professors accounted for $25.9 \%$ and $16.8 \%$, respectively, while $7.6 \%$ were teaching stream faculty. Most were tenured (75.9\%), white (86.1\%), and identified as heterosexual (94.2\%). Over half worked in science-related departments (54.8\%), followed by engineering (20.9\%), agriculture (18.8\%), and other fields (5.5\%), such as environmental sciences.

We calculated gender differences in non-academic interactions using chi-square tests, including Cramer's V analyses of effect size and strength of association. The statistical associations were then contextualized through a comparative analysis of responses to an open-ended question concerning instances that go above and beyond academic learning. The independent and dependent measures are described next, followed by an explanation of the qualitative analysis procedure.

\section{Measures}

The independent variable is faculty gender (male, female, transgender, and non-binary). Less than $2 \%$ of respondents identified as transgender or non-binary. As it 
was impossible to conduct robust statistical analyses, the transgender and non-binary respondents were excluded, and the measure of gender used in these analyses is dichotomous ( $0=$ male, $1=$ female).

\section{Dependent variables}

The outcome variables include two sets of student experience measures and self-reported stress. The first set of experience questions asked faculty the number of times during their career that they have had a student cry in their presence (office or lab), as well as whether students have talked to them about feelings of extreme stress, distress, or longer-term mental health problems. These two items are measured separately on a 4-point Likert scale ( $0=$ never; $1=1-2$ times; 2=3-5 times; $3=$ more than 5 times).

The second set asked faculty whether their students have ever disclosed having suicidal thoughts or engaging in suicidal behaviour; talked about problems with substance abuse (drugs or alcohol); disclosed sexual harassment or assault; or dating physical violence or domestic violence $(0=n 0,1=y e s)$. The suicide, violence, and sexual harassment/assault items were also combined into a standardized index for an independent samples $t$-test. Respondents' scores on these items were combined and converted into z-scores (i.e., mean $=0, s d=1$ ), for group mean comparisons between men and women.

If faculty experienced any non-academic interactions with students, they were asked to indicate how stressful these experiences were (1=not at all/not very stressful; 2=somewhat stressful; $3=$ =very/extremely stressful). Faculty who did not have any of these student experiences were recoded into the "not at all/not very stressful" category.

\section{Qualitative Analysis Procedure}

An open-ended question asked faculty to elaborate on any experiences with students that went above and beyond academic learning. In total, we compiled statements from 122 faculty (63 males and 59 females). This constitutes a response rate of $42.1 \%$ when calculated based on the 290 respondents included in the bivariate analyses (189 men and 101 women). We conducted multiple rounds of open and focused coding, comparing men's and women's statements, including concurrent conceptual memos (Corbin \& Strauss, 1990, 2008). The advantage of these inductive techniques is the ability to generate concepts and associations unrestricted by closed-ended response options. However, our data do not permit a full grounded theory analysis, as we cannot ask probing questions or saturate conceptual categories to the same degree as through in-depth interviews and purposive sampling (Corbin \& Strauss, 1990, 2008). Nevertheless, the constant comparative approach produced highly valid data to complement the statistical analyses.

An initial round of open coding distinguished levels of faculty engagement with students' personal problems: low (e.g., denying conversations), moderate (e.g., giving advice), and high (e.g., defining student success "holistically"). Male and female comments were compared separately and then cross-compared to identify distinguishing features (e.g., the "low engagement" men vs. the "low engagement" women).

Two separate rounds of focused coding further investigated: 1) Gender differences in number of student interactions; and 2) The impact of these interactions on faculty. The first round of focused coding examined faculty behaviour. We looked for descriptions of the concrete steps women and men took, constituting their "responses" to students' disclosures. A total of 61 response-specific comments were compiled (35 male and 26 female). The second round of focused coding emphasized the impact of these interactions on faculty. Only 13 men and 12 women discussed the impact of these encounters for a total of 25 impact-specific statements and, therefore, those results must be interpreted with caution. In each of the focused coding rounds, male and female statements were, again, compared to each other separately and then against one another to refine the different dimensions of men's and women's experiences (e.g., amount of labour performed) (Lofland, J., Snow, \& Lofland, L. H., 2006).

The authors are all white women: two sociologists, who specialize in gender; and one soil scientist, who has been the sole female in her department for 20 years, and whose scholarship and advocacy work promotes the advancement of women in NSE. As such, our work has often prioritized the structural barriers women encounter in gendered contexts. Mindful of this predisposition, we sought to identify similarities in male and female faculty's experiences as much as differences, where appropriate. We did not examine racial differences but are mindful that racial minority status interacts with gender to produce different outcomes for racialized faculty; and that, as white women, we are in a privileged position with respect to race. 


\section{Results}

Univariate results showed that most faculty (88.6\%) had at least one student cry in their presence, with $29.7 \%$ estimating they had this experience with more than five students. Similarly, $90.3 \%$ had at least one student discuss extreme stress, distress, or long-term mental health issues, with $27.7 \%$ indicating that they had more than five students do so. Just under a quarter (23.8\%) had at least one student disclose domestic/dating violence, $27 \%$ had at least one disclose suicidal thoughts, $18.8 \%$ had at least one discuss problems with drug or alcohol abuse, and $29.9 \%$ had at least one disclose sexual assault/harassment. Taken together, almost half (46.2\%) of faculty had at least one student disclose incidents of domestic violence, sexual harassment/assault, substance abuse, or suicidal behaviour.

Bivariate analyses indicated that students disclosed particular issues to comparable proportions of male and female NSE faculty. Nearly all women (97\%) and most men $(84.1 \%)$ had at least one student cry in their presence. Similarly, most women (93.1\%) and men (88.8\%) also had at least one student approach them to discuss extreme stress, distress, or chronic mental health issues during their career. dating violence than men (18.5\%). Women (40.6\%) reported having significantly more discussions involving sexual harassment/assault than men (24.1\%); and suicidal thoughts/behaviour were significantly more likely to be reported to female $(34.7 \%)$ than male $(22.9 \%)$ faculty. An independent samples $t$-test of mean differences further indicated that women $(M=0.33)$ were more likely than men $(M=-0.12)$ to have students disclose dating/domestic violence, sexual assault/harassment, and suicidal thoughts/behaviour ( $t=-3.6, d f=179, p<.001$ ).

When asked about impact, both men and women reported experiencing stress. Almost three-quarters (73.4\%) characterized non-academic encounters as either somewhat, very, or extremely stressful. Yet, consistent with the number and nature of the interactions that women experienced, female faculty (39.6\%) were significantly more likely to find the encounters very or extremely stressful, relative to men (24.9\%) $\left(\chi^{2}=8.2, p<.05, V=.17\right)$. Analyses examining rank (instructor, assistant, associate, and full professor) did not indicate any significant differences in number of interactions or stress. Thus, for our sample, longer careers did not appear associated with a greater number of non-academic interactions. Similarly, we found no significant differences between the five institutions.

Table 1. Gender Differences in Student Interactions.

\begin{tabular}{|lccccc|}
\hline Interaction & Female & Male & $\chi^{2}$ & $d f$ & Cramer's V \\
\hline+5 crying (office or lab) & $43.6 \%{ }^{* * *}$ & $22.2 \%$ & 20.8 & 3 & .27 \\
+5 extreme stress/mental health issues & $32.7 \%$ & $25 \%$ & 5.5 & 3 & .14 \\
Substance abuse & $20 \%$ & $18.1 \%$ & .20 & 1 & .02 \\
Dating or domestic violence & $33.7 \%^{* *}$ & $18.5 \%$ & 8.3 & 1 & .17 \\
Sexual harassment or assault & $40.6 \%^{* *}$ & $24.1 \%$ & 8.6 & 1 & .17 \\
Suicidal thoughts or behaviour & $34.7 \%^{*}$ & $22.9 \%$ & 4.6 & 1 & .13 \\
\hline
\end{tabular}

Note. ${ }^{*} p<.05 .{ }^{* *} p<.01 .{ }^{* * *} p<.001$

However, consistent with gendered care expectations, women (43.6\%) were almost twice as likely as men $(22.2 \%)$ to have in excess of five students come to them in tears. Although female faculty (32.7\%) were also more likely to have more than five students disclose feelings of extreme stress, distress, or longer-term mental health issues than men (25\%), this difference was not statistically significant. However, women (33.7\%) also encountered significantly more disclosures of domestic/
As expected, the statistical analyses demonstrated that women were more likely to be approached by a greater number of students and for serious issues involving violence and suicidal thoughts and behaviour. In addition, the encounters appeared more stressful for women. Nevertheless, it is important to analyze the qualitative data to further contextualize faculty's experiences. 


\section{Number of Student Disclosures: Gen- dered Expectations and Institutional Factors}

Several women connected their number of student interactions to cultural assumptions of women as more interpersonally-inclined, including being compassionate, accommodating, and helpful. One woman noted she has "received the feedback that I am very approachable and responsive to student problems. Compassionate but rational $[. .$.$] ". Women were more likely than men to$ describe weak borders between their personal and work time. At least one prioritized her students' needs: "I make time to help students at all hours and am available most nights until midnight or 1:00 A.M. [...] I do not put a time limit on students when they need assistance".

Overall, these data suggested that female faculty expected more non-academic interactions because of their gender: "As the only female faculty in [my department], I think that students are more likely to approach me with personal concerns than they would my male colleagues". Indeed, several women made reference to gender but only one man referred to it at all (and did so to point out the exceptional nature of discussing sexual assault with a man): "Many students feel comfortable (at least relative to other profs) in talking about these issues [with me], accepting that I am white, male, and middle-aged and so not the obvious go-to person in this regard".

Further, women were more likely than men to express feeling "a responsibility to talk these problems through with students" or that their "presence [is] important for the student's well-being", despite feeling "overwhelmed and totally unqualified to deal and cope with the situations". Asserting student care as their "responsibility" suggested that some women considered it to be part of their role as professors. If students define female faculty's jobs in a similar way (as the statistical results suggest), then refusing to engage with non-academic problems would not expose male faculty to the same professional risks (e.g., poor student evaluations). Refusals from female faculty, however, may result in negative judgments of both their job and gender "performance".

In addition, institutional roles and course topics may increase the number of non-academic interactions (Barnes-Powell \& Letherby, 1998; Nadler, M. K. \& Nadler, L. B., 1993). A few women linked large undergraduate classes, coordinating undergraduate courses, and men- tal health course components to care work. One commented that, "as a teaching stream faculty member who deals almost exclusively with large enrollment courses, just by statistical laws I have some students in distress in my course every term. [...]. [M]ost struggling students end up in my office eventually". Similarly, another noted that she "was teaching a course on professional development and I would discuss mental health issues with the students. This generally resulted in students coming to my office with several of these disclosures".

In contrast, men did not reference their teaching duties. Thus, to the extent that faculty (male or female) have greater responsibility for undergraduate courses or are more likely to have mental health-related course content, we may expect them to have more non-academic student interactions. Indeed, a handful of both men and women noted that, during their time as senior administrators, it was their "job to deal with distress[ed] students' problem cases":

I served briefly as the Associate Dean. During this period, I had to deal with four sexual assault cases, two cases of physical/verbal abuse, two cases of instructor misconduct, in addition to the monthly pantheon of student academic misconduct (plagiarism, etc.). Several of these cases involved engagements with lawyers for plaintiffs and the accused. I found these situations very stressful. (male)

The qualitative results are generally consistent with the cultural and institutional findings put forth in the existing literature. However, because only a handful of female faculty commented on the connection between teaching roles and numbers of student interactions, these results should be interpreted with caution. We now turn to an examination of gender differences in stress.

\section{Stress: Gendered Approaches to Student Problems}

The qualitative analysis yielded three types of faculty responses, reflecting either low, moderate, or high engagement with students' personal lives: 1) distancing, 2) listening and directing to support services, and 3) proactive prevention. Contrary to Statham and colleagues' (1991) findings that U.S. male faculty were more likely to avoid outside-of-class personalizing with students than female faculty, there was no obvious gender difference 
in Canadian NSE faculty's responses. Roughly the same proportion of men and women employed each response, highlighting the importance of within-gender variation (i.e., not all women engage with student's personal problems).

\section{Distancing}

A few male and female faculty members preferred to compartmentalize their role as professors through "polymorphism". Thus, university interactions were limited to "strictly professional encounter[s]". This reaction contradicts expectations of feminine care, possibly increasing women's risk of being penalized by students if they take this approach (Bennett, 1982). In contrast, the male "distancers" worried that they "could easily be accused of anything" and felt it was better to remain "on the side", implying they risk institutional consequences, as opposed to gender sanctions:

I try to have fewer personal interactions with students than in the past because 1) they are stressful, 2) it's easy to get blamed for doing the wrong thing, and 3) I've had a previous university administrator blame me unfairly for a problem... (male)

At the surface level, men also linked "distancing" with a lack of training (e.g., worried about "doing the wrong thing"). Indeed, feeling ill-equipped to handle mental health problems was the most common theme across gender and explained why the majority of male and female faculty preferred to listen and direct students to qualified professionals.

\section{Listen and direct}

"Listen and direct" required a moderate degree of faculty engagement and there were notable differences in the way that men and women "listened and directed" that are relevant to women's significantly higher levels of reported stress. The men's approach required a smaller investment of time and effort, as most made no mention of additional steps taken to aid students. One man explained that he was "completely ill-equipped to deal with student mental health issues, but...happy to give time and to listen, and to direct to university resources".

In contrast to female faculty, who were more likely to assert it was their "responsibility" to support students' well-being, men's style of "listen and direct" established a boundary between personal and academic matters: "I know my limits. I serve as a sounding board, and engage the appropriate mental health services [...]". Even the few men in this group who indicated they would take additional steps restricted these to giving personal advice, consulting with their immediate superior (or others), and giving course concessions.

The relatively arm's length personal involvement of the men who "distanced" themselves and "listened and directed" to services may be evidence that they, too, are doing their gender (West \& Zimmerman, 1987); and/or engaging in emotional labour by pursuing institutionally-appropriate options, such as talking to their superior (Hochschild, 2012). If male faculty employ a lower effort response, even if approached by multiple students for serious reasons, this might help limit men's stress. Indeed, even though the statistical results indicated that $24.9 \%$ of men found their student interactions very or extremely stressful, overall, men's comments rarely mentioned stress. Lower reports of stress are, themselves, consistent with cultural perceptions of men being emotionally "stronger" than women, so men may have felt more comfortable discussing guilt or regret. One particular man linked his regret to action he would have taken (and implied these actions would have been successful), reflecting understandings of men as more agentic, assertive, and competent than women (e.g., Eagly \& Wood, 2012):

We have had our share of problems over the years, including... to my great regret, one who committed suicide. I still regret that I failed to recognize the warning signs for what they were and that I therefore failed to act to prevent this. (male)

The women's "listen and direct" approach was more likely to include additional assistance, which required extra time and engagement: "I have supported (walked over or counselled) numerous students to seek assistance from disability services for issues ranging from [Attention Deficit Disorder] and depression to migraines". Insofar as this is the case, additional efforts are consistent with expectations of greater care and concern from women. Compared to men, women's "listen and direct" reflected greater ownership of students' well-being, even when passing the labour on to a trained professional:

I do not have any professional training but do listen and often suggest that they seek professional as- 
sistance. On numerous occasions I have personally walked individuals in distress to the medical facility on campus and waited with them until they were seen by a physician. (female)

Consequently, a larger expenditure of effort and time (perhaps multiplied by a greater number of students disclosing serious problems, like sexual assault) may require more emotional labour and/or contribute to women's stress. Thus, by doing their respective genders, female faculty may be at greater risk for stress, while male faculty might be better protected from it.

\section{Proactive prevention}

A few faculty members described taking the proactive prevention approach, which involved the greatest engagement with students' personal lives. These faculty were rated higher on engagement because they connected students' personal and academic lives, checking-in with students to see how they are doing throughout the term, and defining success holistically (i.e., more than grades), for example:

I have worked with supervisors that are interested not only in my academic growth but also my personal [...] well-being. I seek to do the same for my students and am [a] very approachable person when they need to talk about quite a variety of issues. (female)

Inquiring about students' personal lives seems more consistent with expectations of care from women than men. Yet, to the extent that preventive action ensures students' and faculty's scholarly activities are not affected by personal problems, this approach could also be consistent with doing gender for men (e.g., taking control).

The qualitative results indicated that women and men responded to non-academic student problems in similar ways while still "doing" their respective genders (West $\varepsilon$ Zimmerman, 1987). Most became moderately engaged; listening and directing to support services. The clearest gender difference was in the greater amount of time and effort some women appeared to have invested when they "listened and directed", relative to men. However, there was one additional gender difference that may also be relevant to women's stress levels: negative professional consequences.

\section{Professional consequences}

Female faculty could be so impacted by student disclosures that they needed to stop working: "the experiences were extremely stressful for me and generally resulted in my leaving my work for the day to be able to clear my head, once the immediate danger to the student was resolved". Another was proud that she helped one student through a series of problems but felt, at times, it was difficult to maintain her research program. However, these problems could also simply appropriate the time that would, otherwise, be spent elsewhere:

All the time I spend on the "human" side of teaching, I do at the cost of my research, or at the cost of my own personal life. There are 24 hours in a day, and if I spend two counselling a student, that's two hours I don't read, write, or sleep. (female)

Thus, women's stress might also be an indirect product of not having enough time to focus on primary work activities. There was no evidence suggesting that one type of faculty response was more likely to result in negative professional effects. Regardless, no men reported any negative effects on their work productivity, as a result of students' personal problems.

\section{Discussion}

Our analysis indicates that many Canadian university students are dealing with serious personal and mental health problems, including physical/sexual violence and suicidal thoughts and behaviour. The majority of NSE faculty encounter a variety of student disclosures during their career, most try to help, and these interactions are often stressful. However, female NSE faculty appear to have a heavier student care load, which may cause significantly more stress or impede scholarly work (Acker \& Feuerverger, 1996). As such, this labour could be another gender-based obstacle to NSE women's equality within already gendered academic units. Since cultural care expectations are not limited to NSE faculty, we join other scholars in asserting that the care gap is relevant to understanding the extent to which gender inequality is embedded within the structure of universities (Bellas, 1999; Bird et al., 2004). This labour illustrates two processes argued to gender organizations: interactions wherein actors replicate gender; and the ways in which individuals construct appropriately gendered identities 
for their institutional setting (Acker, 1990).

Nevertheless, roughly the same proportion of male and female faculty employed low, medium, and high engagement responses, contrary to some existing American evidence (Statham et al., 1991). The absence of a clearer gender division may be a product of our particular sample. Perhaps women in NSE feel more pressure to embody "masculine" behaviours because of their male-dominated work environments, as opposed to female faculty in the more "women-friendly" humanities, for example. Likewise, the underrepresentation of women in NSE may mean students have no choice but to approach a male faculty member to discuss their troubles, eliciting greater involvement from men. Thus, limiting the sample to NSE could have reduced some of the gender differences.

Similarly, our data suggest that some teaching and senior administrative positions may exacerbate care loads. More research is required to understand the degree to which these patterns are gendered and unique to NSE; for example, are NSE men more likely to hold senior administrative positions? Are "token" NSE women more or less likely than female faculty from more gender-balanced units to teach large undergraduate classes (Kanter, 1977)? Future research comparing different disciplines would help explain how work contexts affect student care responsibilities.

\section{Limitations and Policy Recommenda- tions}

Our survey's response rate is relatively low (22\%). As such, our findings cannot be generalized to all Canadian NSE faculty and additional research examining this population is necessary. Nevertheless, our sample size is sufficient to conduct the bivariate statistical and qualitative analyses described here.

In addition, we were unable to directly observe faculty-student interactions, which limits our ability to examine actors' thought processes. To that end, it would be beneficial for future studies to carry out a more focused faculty survey on the topic of student care labour; or in-depth interviews with students and faculty to gain more insight into why certain faculty members are approached; how much time faculty spend caring for students; how gender may be reproduced through these encounters (e.g., why faculty react as they do); the personal and professional consequences for male and female faculty; and whether stress is a direct or indirect result of students' problems (e.g., taking time away from research). Interviews may also permit a deeper exploration of the emotional labour that faculty perform (Hochschild, 2012).

Even though the conclusions derived from the qualitative data cannot be generalized beyond this sample, two policy recommendations are still evident. First, student care work is not officially recognized (Acker \& Feuerverger, 1996). To appropriately credit faculty's care efforts, a systematic method of tracking is required (e.g., within annual activity reports or tenure and promotion documents). Second, most faculty feel unprepared to manage mental health disclosures (e.g., Storrie, Ahern, \& Tuckett, 2012):

I felt overwhelmed and totally unqualified to deal and cope with the situations [...] these experiences have required skills way above what my training had provided me with. It might be a good idea to prepare professors with such training to ensure that students' health and safety are considered. (female)

Confiding in faculty is an encouraging sign for de-stigmatizing students' mental health challenges (Stanley \& Manthorpe, 2001). However, student and faculty well-being may be enhanced if universities explicitly recognized and valued student care labour (including mental health crisis response training for faculty). Moreover, a culture shift regarding the value of student care work may positively affect the retention of female and racial minority NSE students, specifically (e.g., Amelink \& Creamer, 2010). Students may be more likely to perceive that trained faculty, who are willing and equipped to address students' non-academic challenges, respect them and care about their learning, supporting their continued participation in NSE programs (e.g., Amelink \& Creamer, 2010).

\section{Conclusion}

Most academic faculty are not trained counsellors. Nevertheless, they may be called upon to serve in this role and, thus, the gendered nature of this work must be acknowledged. A care gap would be further evidence of a hierarchical division of labour, with women bearing a greater responsibility for the most devalued job: "taking care of the academic family" (Guarino \& Borden, 2016, p. 19). As such, student care work may act as yet anoth- 
er structural constraint on female faculty's time and may diminish their well-being, better positioning men to focus on more institutionally valued tasks, like research (Bird et al., 2004; Misra et al., 2011; Winslow, 2010).

\section{Acknowledgements}

The authors are grateful to the two anonymous reviewers for their comments and suggestions; and would like to thank the Natural Sciences and Engineering Research Council Women in Sciences and Engineering Program for supporting this research.

\section{References}

Acker, J. (1990). Hierarchies, jobs, bodies: A theory of gendered organizations. Gender \& Society, 4(2), 139-158. https://doi. org/10.1177/089124390004002002

Acker, S., \& Feuerverger, G. (1996). Doing good and feeling bad: The work of women university teachers. Cambridge Journal of Education, 26(3), 401-421. https://doi.org/10.1080/0305764960260309

Acker, S., Webber, M., \& Smyth, E. (2012). Tenure troubles and equity matters in Canadian academe. British Journal of Sociology of Education, 33(5), 743-761. https://doi.org/10.1080/01425692.2012.6 74784

Amelink, C. T., \& Creamer, E. G. (2010). Gender differences in elements of the undergraduate experience that influence satisfaction with the engineering major and the intent to pursue engineering as a career. Journal of Engineering Education, 99, 81-92.

Bagilhole, B., \& Goode, J. (1998). The 'gender dimension' of both 'narrow' and 'broad' curriculum in UK higher education: Do women lose out in both? Gender and Education, 10(4), 445-458. https://doi. org/10.1080/09540259820862

Barnes-Powell, T., \& Letherby, G. (1998). 'All in a day's work': Gendered care work in higher education. In D. Malina \& S. Maslin-Prothero (Eds.), Surviving the academy: Feminist perspectives (pp. 69-77). Philadelphia, PA: Falmer Press.

Bellas, M. L. (1999). Emotional labor in academia: The case of professors. Annals of the Academy of Political and Social Science, 561, 96-110.

Bennett, S. K. (1982). Student perceptions of and expectations for male and female instructors: Evidence relating to the question of gender bias in teaching evaluation. Journal of Educational Psychology, 74(2), 170-179. http://psycnet.apa.org/ doi/10.1037/0022-0663.74.2.170

Bird, S. R. (2011). Unsettling universities' incongruous, gendered bureaucratic structures: A casestudy approach. Gender, Work and Organization, 18(2), 202-230. https://doi.org/10.1111/j.14680432.2009.00510.x

Bird, S., Litt, J., \& Wang, Y. (2004). Creating status of women reports: "Institutional housekeeping as "women's work". NWSA Journal, 16(1), 194-206. https://www.jstor.org/stable/4317042

Canadian Association of University Teachers. (April, 2018). Underrepresented $\&$ underpaid: Diversity $\varepsilon$ equity among Canada's post-secondary teachers. Retrieved from https://www.caut.ca/sites/default/ files/caut equity report 2018-04final.pdf.

Corbin, J. \& Strauss, A. (2008). Basics of Qualitative Research: Third Edition. Thousand Oaks, CA: Sage Publications Inc.

Corbin, J. \& Strauss, A.(1990). Grounded Theory Research: Procedures, Canons and Evaluative Criteria. Zeitschrift für Soziologie, 19(6), 418-427.

Eagly, A. H., \& Wood, W. (2012). Social role theory. In P. van Lange, A. Kruglanski \& E. T. Higgins (Eds.) Handbook of theories in social psychology (pp. 485-476). Thousand Oaks, CA: Sage Publications. https://doi.org/10.4135/9781446249222.n49

Fox, M. F. (2010). Women and men faculty in academic science and engineering: Social organizational indicators and implications. American Behavioral Scientist, 53(7), 997-1012. https://doi. org/10.1177/0002764209356234

Guarino, C. M., \& Borden, V. M. H. (2016). Faculty service loads and gender: Are women taking care of the academic family? IZA Discussion Papers, no. 10010. 
Hochschild, A. R. (2012). The Managed Heart: Commercialization of Human Feeling. Berkeley, CA: University of California Press.

Kanter, R. M. (1977). Some effects of proportions on group life: Skewed sex ratios and responses to token women. American Journal of Sociology, 82(5), 965-990. https://doi.org/10.1086/226425

Lofland, J., Snow, D., \& Lofland, L. H. (2006). Analyzing Social Settings: A Guide to Qualitative Observation and Analysis: Fourth Edition. Toronto, ON: Nelson.

Mahoney, K. T., Buboltz, W. C., Buckner, J. E., \& Doverspike, D. (2011). Emotional labor in American professors. Journal of Occupational Health Psychology, 16(4), 406-423. https://doi.org/ 10.1037/ a0025099

Misra, J., Lundquist, J. H., Holmes, E., \& Agiomavritis, S. (2011). The ivory ceiling of service work. Academe, 97(1), 22-26.

Mottarella, K. E., Fritzsche, B. A., \& Cerabino, K. C. (2004). What do students want in advising? A policy capturing study. NACADA Journal, 24(1 \& 2), 48-61. https://doi.org/10.12930/0271-9517-24.1-2.48

Nadler, M. K. \& Nadler, L. B. (1993). The influence of student sex and instructor sex on academic advising communication. Journal on Excellence in College Teaching, 4, 119-130.

Ogbonna, E., \& Harris, L. C. (2004). Work intensification and emotional labour among UK university lecturers: An exploratory study. Organization Studies, 25(7), 1185-1203. https://doi. org/10.1177/0170840604046315

O'Meara, K. (2016). Whose problem is it? Gender differences in faculty thinking about campus service. Teachers College Record, 118(080306), 1-38.

Ornstein, M., Stewart, P., \& Drakich, J. (2007). Promotion at Canadian universities: The intersection of gender, discipline, and institution. The Canadian Journal of Higher Education, 37(3), 1-25.

Park, S.M. (1996). Research, teaching, and service: Why shouldn't women's work count? The Journal of Higher Education, 67(1), 46-84. https://doi.org/10.1 080/00221546.1996.11780249
Pyke, K. (2011). Service and gender inequity among faculty. Political Science \& Politics, 44(1), 85-87. https://doi.org/10.1017/S1049096510001927

Settles, I. H., Cortina, L. M., Malley, J., \& Stewart, A. J. (2006). The climate for women in academic science: The good, the bad, and the changeable. Psychology of Women Quarterly, 30(1), 47-58. https://doi.org/10.1111/j.1471-6402.2006.00261.x

Stanley, N., \& Manthorpe, J. (2001). Responding to students' mental health needs: Impermeable systems and diverse users. Journal of Mental Health, 10(1), 41-52. https://doi.org/10.1080/209638230020023606

Statham, A., Richardson, L., \& Cook, J. A. (1991). Gender and university teaching: A negotiated difference. Albany, NY: State University of New York Press.

Storrie, K., Ahern, K., \& Tuckett, A. (2012). Crying in the halls: Supervising students with symptoms of emotional problems in the clinical practicum. Teaching in Higher Education, 17(1), 89-103. https://doi.org/10. 1080/13562517.2011.590980

West, C., \& Zimmerman, D. H. (1987). Doing gender. Gender \& Society, 1(2), 125-151. https://doi. org/10.1177/0891243287001002002

Winslow, S. (2010). Gender inequality and time allocations among academic faculty. Gender \& Society, 24(6), 769-793. https://doi. org/10.1177/0891243210386728

\section{Contact Information}

Jennifer Dengate

Jennifer.Dengate@umanitoba.ca 